\title{
http://dx.doi.org/10.35381/racji.v5i1.635
}

\section{Las medidas cautelares en materia constitucional en el Ecuador}

\section{Constitutional precautionary measures in Ecuador}

\author{
Fabián Marcelo Salinas-Herrera \\ fsalinash@ucacue.edu.ec \\ Universidad Católica de Cuenca, Cuenca \\ Ecuador \\ https://orcid.org/0000-0001-6468-1878 \\ Cecilia Ivonne Narváez-Zurita \\ inarvaez@ucacue.edu.ec \\ Universidad Católica de Cuenca, Cuenca \\ Ecuador \\ https://orcid.org/0000-0002-7437-9880 \\ José Luis Vázquez-Calle \\ jlvazquezc@ucacue.edu.ec \\ Universidad Católica de Cuenca, Cuenca \\ Ecuador \\ https://orcid.org/0000-0003-4980-6403 \\ Juan Carlos Erazo-Álvarez \\ jcerazo@ucacue.edu.ec \\ Universidad Católica de Cuenca, Cuenca \\ Ecuador \\ https://orcid.org/0000-0001-6480-2270
}

Recibido: 13 de noviembre de 2019

Aprobado: 17 de diciembre de 2019

\section{RESUMEN}

Se analizan las medidas cautelares de protección, como un elemento de garantía de los derechos humanos reconocidos en la Constitución Ecuatoriana. El estudio se basa en las características de las mismas, enfocando como tema las medidas cautelares en materia constitucional en el Ecuador. Se analiza la justificación de las medidas 
cautelares, vistas desde sus características, presentación, admisibilidad de la misma. En base a esto se establece como problemática la ineficaz protección de los derechos consagrados en la Constitución del Ecuador. El objetivo es analizar las medidas cautelares constitucionales en el Ecuador como mecanismo de protección eficaz e inmediata. La Metodología utilizada fue el análisis bibliográfico documental. Como conclusión se obtuvo que las medidas cautelares se encuentran bien fundamentadas desde las leyes que la cimientan, y que se da al juez la entera competencia de dictar sentencias basadas en este principio constitucional.

Descriptores: Medidas cautelares; garantías jurisdiccionales; constitución; ley orgánica de garantías constitucionales y control constitucional.

\section{ABSTRACT}

Precautionary protection measures are analyzed, as an element of guarantee of human rights recognized in the Ecuadorian Constitution. The study is based on their characteristics, focusing on precautionary measures in constitutional matters in Ecuador. The justification of the precautionary measures, based on their characteristics, presentation, admissibility, is analyzed. Based on this, the ineffective protection of the rights enshrined in the Constitution of Ecuador is established as problematic. The objective is to analyze the constitutional precautionary measures in Ecuador as an effective and immediate protection mechanism. The methodology used was the documentary bibliographic analysis. In conclusion, it was obtained that the precautionary measures are well founded from the laws that underlie it, and that the judge is given full jurisdiction to issue sentences based on this constitutional principle.

Descriptors: Precautionary measures; jurisdictional guarantees; Constitution; organic law of constitutional guarantees and constitutional control.

\section{INTRODUCCIÓN}

El objeto del Derecho Constitucional es el estudio de la constitución y su relación de los individuos con los distintos órganos gubernamentales, de manera concreta se pueden indicar que el Derecho Constitucional se encarga del estudio de los derechos humanos, teniendo en cuenta que es la norma suprema y que se encuentra sobre todas las leyes de la República (Pérez y Merino , 2009).En este contexto, la Constitución del Ecuador del año 2008, en cuanto, a su aspecto procedimental se refiere de manera sucinta a las medidas cautelares constitucionales y propone que pueden pedirse en forma autónoma 
o conjunta con otras garantías del mismo tipo, más aun siendo el Ecuador un país garantista de derechos y como lo determina el artículo, 1 de la Carta Magna, el mismo que indica que su aplicación es directa e inmediata (Asamblea Constituyente, 2008).

Por lo tanto, es fundamental conocer esta figura constitucional, que en las distintas unidades jurisdiccionales se han conformado en forma variada, aun no existen normas claras, sobre el manejo de estas medidas, aunque se han creado la Ley Orgánica de Garantías Jurisdiccionales y Control Constitucional (Asamblea Nacional, 2009) que manifiesta que las medidas cautelares se basan en la consecución del derecho debido a que todos los sujetos tienen derecho a ejercer esta garantía constitucional de conformidad con los patrones internacionales de proporcionalidad establecidos. Estas medidas no crean derechos, los protegen, por lo que entran o actúan cuando estos ya tienen existencia jurídico-constitucional y están en pleno funcionamiento, por consiguiente, actúan donde existe la amenaza objetiva de violación de los derechos (Zaidan , 2015).

Por lo expuesto, el estudio del artículo se basa en el tema de las medidas cautelares en materia constitucional en el Ecuador y por esto se establece la problemática de cómo determinar la protección eficaz e inmediata de los derechos consagrados en la Constitución del Ecuador. Por este motivo se recurre a un estudio de las características de las acciones cautelares desde la sumariedad, la urgencia, la preventividad, la mutabilidad, la taxatividad, y con la comprensión de cada una de estas características conseguir que sean aplicadas en forma idónea.

Se debe entender que las medidas cautelares son propuestas en forma autónoma, facilidad que presta el sistema judicial de primera instancia, los operadores de justicia juezas y jueces que son generalmente nuevos, que incluso son posesionados sin experiencia, no pueden entender el accionar de estas medidas, esperan se desarrolle el proceso para conocer mejor la garantía jurisdiccional que está siendo solicitada (Benavides, 2013). 
La constitución regula el actuar de los jueces y juezas, por lo que se debe entender que los administrados pueden solicitar ante un juez dichas medidas de protección y de no ser concedidas el usuario está en la facultad de poner un reclamo administrativo a dicho juez, esto implica que debe existir conocimiento por parte de los administrados y de los jueces que hacen la práctica diaria de la justicia, quienes son los llamados para hacer respetar los derechos consagrados en la constitución (Grijalva, 2012).

Los jueces administran la justicia y dan paso los casos de la materia asignada, a excepción de los jueces multicompetentes que existen en el sistema judicial ecuatoriano, por lo que esta circunstancia deriva que se aplique en forma correcta esta garantía jurisdiccional que son las medidas cautelares constitucionales, por consiguiente los jueces y juezas deben tener la capacidad de seguir los principios constitucionales, regidos por la ética y moral esto es parte del desafío que los jueces deben hacer por el desconocimiento de los administrados para precautelar sus derechos (García, 2002).

Ante el escenario descrito, la presente investigación tiene por objetivo analizar las medidas cautelares constitucionales en el Ecuador como mecanismo de protección eficaz e inmediata de los derechos consagrados en la Constitución. Todo esto basado en análisis de la información de una manera práctica y estableciendo los parámetros que se fundamentan en la formulación de las medidas cautelares como son el periculum in mora el peligro en la demora y el fumis nobi iuris la apariencia del buen derecho. Esto como elementos de actuación de un correcto manejo de este principio constitucional. Entendido como la celeridad y pericia que se debe dar a los procesos judiciales por parte de los jueces competentes.

\section{DESARROLLO.}

\section{Origen, definición y objeto de las medidas cautelares constitucionales}

Para el estudio de las medidas cautelares, es necesario trasladarnos a la época del derecho romano (753 a.C.), aquí se hace mención a la figura de la interdicción, la cual 
tiene similitud con lo que hoy son las medidas cautelares. El objeto de la misma era alejar a una persona para que no produzca daño (Vaca, 2017). En el Ecuador se comienza hablar de las medidas cautelares con la implementación de esta figura en la Constitución de 1998, como medidas urgentes, en tanto que, en la constitución del 2008 tiene el nombre de medida cautelar constitucional (Uribe, 2012). El término cautelar, proviene del latín cautela, que quiere decir prevenir o precaver. Lo que supone y está inmerso en las medidas cautelares como un método de precautelar los derechos de las personas.

En el mismo sentido, Cantor (2008) afirma "que las medidas cautelares pueden ser entendidas como la adopción de las disposiciones para prevenir un daño o peligro cuando las circunstancias lo impongan" (p.9). Bajo este contexto, las medidas cautelares constitucionales son garantías establecidas jurídicamente para que el titular de un derecho asegure, en forma rápida su acción, con el fin de prevenir que se vulnere los derechos y exista un peligro inminente. Para afirmar el resultado de la resolución definitiva. La misma tiene objetos múltiples esto según Ávila (2011) "a) prevenir la violación de un derecho constitucional; b) interrumpir la violación de un derecho constitucional; c) evitar la amenaza de violación de un derecho constitucional; y, d) evitar la violación de un derecho constitucional" (p.23). A esto se suma lo que plantea Castillo (2009) que "la finalidad de estas medidas cautelares es evitar o cesar la amenaza o violación de los derechos reconocidos en la constitución o en otros instrumentos internacionales" (p.17)

Los autores que hablan sobre las medidas cautelares, establecen que esta medida judicial tiene como fin la eficacia de la justicia, analizado desde la doctrina jurídica y en virtud de esto los derechos consagrados puedan ser ejecutados eficaz e íntegramente. En este proceso al obtenerse la eficacia de la administración de justicia, los derechos que se estipulan en la constitución pueden hacerse efectivos, manteniendo así la seguridad jurídica de un Estado (Marcheco, 2017). Por lo tanto, la Corte Constitucional analiza los cimientos que justifican la existencia de las medidas cautelares, las cuales 
son la base del desarrollo del principio de eficacia de la administración de justicia. En tanto que, existe la necesidad de que se promuevan mecanismos cautelares que ratifiquen la valía de las decisiones judiciales, ya que pueden establecerse problemas que afecten el debido proceso.

En si la Corte Constitucional debido a estas tensiones y enmarcada en los ordenamientos jurídicos, establece una serie de criterios para que se pueda sustentar una medida cautelar, los mismos deben acoplarse a un análisis desde la racionalidad y proporcionalidad (Storini , 2013). La misma Corte Constitucional considera que las medidas cautelares son actos mediante los cuales los jueces pueden adoptar las medidas necesarias, en defensa del derecho material y garantizar el debido proceso. Esta medida se enfrenta a una serie de discrepancias que nacen desde la aplicabilidad de la misma, generando una delimitación conceptual, aunque tiene la aceptación en un juicio, esta no es unánime, por lo tanto esa protección de los derechos se obtiene en los denominados procesos cautelares (Storini , 2013). Por otro lado, se establece que estas medidas por su carácter y fundamentación son autónomas.

En este mismo sentido, se ha establecido tratados multilaterales que permiten un fiel cumplimiento de las medidas cautelares en los Estados miembros de la Organización de Estados Americanos (OEA). En el cual se ratifican estos preceptos a las cuales se las denominan medidas cautelares, su accionar radica en un procedimiento o medio que garantice el efecto en procesos de naturaleza civil, laboral, comercial (Steiner y Uribe , 2012). Los alcances que tendrá la misma se remitirán a garantizar la custodia de hijos menores, el cumplimiento de garantías para la seguridad de los bienes, tales como secuestros preventivos de bienes inmuebles, administración de empresas, y embargos. En tanto que dicha ley será aplicable y se ejecutará según los jueces del lugar del proceso, si como la contra cautela o garantía del proceso. Por lo tanto, la aplicación de la ley estará en manos de los jueces competentes, quienes serán los que regulen la aplicabilidad de la ley, y fundamenten su accionar, las limitantes se basaran en los 
parámetros de la ley y su contemplación será motivo de esclarecimientos jurídicos, en base a las normas judiciales de sustento del derecho positivo (Vaca, 2017).

\section{Características de las medidas cautelares constitucionales}

Las aproximaciones que se lleguen a dar sobre la naturaleza jurídica de esta medida constitucional, se fundamentan o se asignan a un conjunto de características cuya funcionalidad radica y determinar su existencia, entre las más fundamentales se tiene: la sumariedad, la urgencia, la preventividad, la mutabilidad, la taxatividad. Las medidas cautelares se fundamentan como el cimiento de los preceptos jurídicos, anclados a planteamientos taxativos que imprimen en las leyes lineamientos constitutivos, a continuación, se analizaran las características más determinantes de estas medidas (Kostenwein, 2017).

La jurisdiccionalidad, se basa en que el legislador es el que establece las condiciones, para que los particulares cumplan la función de administrar justicia. Es menester según Restrepo (2010) si los jueces están habilitados para decretar y levantar medidas cautelares nada impide que la ley les atribuya los árbitros esa misma facultad. Es decir, los parámetros de actuación de los jueces se remiten a sus jurisdicciones y por lo tanto se establecerán las características propias de su mandato judicial (Hernández, 2007).

Por otro lado, está la provisionalidad, la cual señala que las medidas cautelares son contingentes, y en medida de los posible podrán ser aceptables de modificarse 0 suprimirse, ofreciendo una contragarantía al sujeto afectado. Esta se puede modificar con una transitoria de la Corte Constitucional en la cual se exponga acuerdos de cooperación judicial (lbídem). En tanto que, la sumariedad es otra característica fundamental que se sustenta en la urgencia de conocer el proceso y así no se vulnera el principio constitucional, sobre todo la buena fe; el propósito es intentar sustraer un fallo advero (Guzmán Chávez, 2019).

En este orden de ideas, la Corte Constitucional, avala la urgencia de las medidas cautelares en los que se menciona las imperfecciones del ser humano, ya que se podría 
pensar que las personas atacarían el orden jurídico sin acatar la ley. Y por último se señala la taxatividad la cual se fundamenta en la aplicación de la potestad cautelar en las acciones de tutela, es así que la Corte Constitucional establece que las medidas cautelares deben responder a requisitos de la Constitución y deben ser autorizadas por el legislador (Marcheco, 2017).

Esta característica de las medidas cautelares, sustentan jurídicamente la aplicación fáctica de procedimientos regulados por la ley, en los que se encomienda el debido proceso, estas características a la vez sustentan la valía de este procedimiento, el cual se basa en estructurar sentencias que aborden los principios del derecho positivo, en el cual el juez dicte sus sentencias basado en los lineamientos que se establecen en la ley (Carrera, 2011). En este sentido, no existe uniformidad en la concepción de las medidas cautelares, ya que su entendimiento se supedita a varios factores inmersos en la concepción misma de estas medidas, que por su naturaleza compleja abarcan elementos como: la instrumentalidad ya que se supeditan al proceso principal de cual dependen y efectivizan su accionar en la efectividad que se dé a las sentencias (Programa Andino de Derechos Humanos, 2010). Otro de los elementos es la provisionalidad, que es una característica intrínseca dada de la condición del proceso y subsisten hasta que se dé una sentencia.

En si los elementos de esta figura se enfrentan a la revocabilidad, es decir, por su carácter de no ser una resolución final sino únicamente provisional esta se enfrenta a una condición de revocabilidad expresa, tomando en cuenta las condiciones fácticas del momento de otorgamiento. Con los elementos señalados anteriormente se generan los fundamentos por los cuales las medidas cautelares pueden darse en concesión. Estos requisitos nacen desde la pericia del juez, el cual está basado en dos preceptos doctrinarios: la apariencia del buen derecho fumus boni iuris y el peligro en la demora periculum in mora (Flores, 2017). Las dos referencias hacen hincapié el presupuesto de la concesión de la medida cautelar reconocidas en la LOGJCC 


\section{Características, procedimiento, competencia y sujetos procesales de las medidas cautelares constitucionales}

Si se analiza estas medidas desde la naturaleza jurídica, su estructura se enfrenta a una dicotomía, por un lado, se la considera como un proceso facilitador que se establece en paralelo al proceso principal, que se añade a la ejecución del mismo. Por otro lado, existen otras personas que lo definen como un proceso que se anticipa a los elementos que se darán de forma futura, ahora bien, es necesario señalar que por sí sola no justifica esta medida.

El otorgamiento de las medidas cautelares se basa en supuestos, que deben ser fundamentados, ordenados y analizados ya que dichas medidas no constituyen una lesión al derecho a la defensa, sino que se sustentan como un diferimiento de procesos. Por lo tanto, el destinatario de estas medidas podrá revocar e impugnar dichas medidas si se demuestra que no son bien fundamentadas (Cueva, 2017). Como se puede observar la naturaleza y procedencia de estos procesos se convierten en la base misma de las medidas cautelares.

Con los elementos expuesto, se analiza la procedencia de las medidas cautelares, las cuales a nivel jurídico están ceñidas a la norma constitucional y deben presentar ciertos requisitos, como: la causa, el tiempo, el objeto, todos estos acoplados a la verosimilitud de las circunstancias de petición cautelar (Corte Interamericana de Derechos Humanos, 2012) Al respecto, la Corte Constitucional tiene o debe aplicar la doctrina necesaria para mostrar cuales son los presupuestos de procedencia, entre los elementos debe estar que el demandante establezca una prueba que fundamente o aporte que su pretensión está fundada, por lo menos en apariencia. Por otro lado, se debe presentar garantías las cuales cubran posibles daños o perjuicios ocasionados si en lo posterior se demuestran que eran infundada (Garcia, 2013). Los lineamientos que demuestran que esta medida está fundamentada en el derecho positivo, y que se promulga como un elemento bien fundamentado en la consecución jurídica del derecho. 
También es necesario analizar un factor preponderante en el establecimiento de las medidas cautelares esto es la existencia del peligro (periculum in mora), el cual señala que los procesos judiciales pueden verse afectados por factores exógenos al procedimiento jurídico regular, debido a que no se cumple el plazo establecido por la Corte Constitucional, lo que afecta significativamente los derechos litigiosos, es así que, por la necesidad de contar con una justicia inmediata se ha recurrido a formular las medidas cautelares que mantienen el equilibrio procesal, que se rige en lineamientos de equidad jurídica que garantizan por un lado los derechos humanos, y por otro, la accesibilidad a los sistemas de justicia (Due Process of Law Foundation, 2013).

Para entender mejor este principio el periculum in mora y según lo establece Monereo (2007) "el periculum in mora es la base de las medidas cautelares, la cual se puede en algunos casos obviar con la tutela ordinaria, sino que este retardo podría generar un daño a la providencia definitiva" (p.43). Esto generaría inequívocamente una lentitud en los procedimientos judiciales. Es inevitable que en todo proceso se dé una demora, por la naturaleza misma de las investigaciones y la recolección de pruebas, por lo que esta demora podría generar daños de procedencia o detrimentos mayor al que se pueda estar dando. Por lo que se debe fundamentar el peligro de la demora, con el fin de evitar ciertos inconvenientes (Corte Interamericana de Derechos Humanos, 2012).

En este marco de referencia, acotando y esgrimiendo los principios o requisitos que rigen las medidas cautelares, está la Fumus boni iuris, o la verosimilitud que debe existir en todo proceso, este involucra que al contrario de lo que sucede en un proceso principal, en el proceso cautelar el juez no debe alcanzar una resolución definitiva, es decir, esta debe ser provisional, ya que puede modificarse el proceso, lo cual formularia unas nuevas circunstancias. Ante lo indicado, el profesor Kielmanovich (2002) señala que las medidas cautelares "no exigen un examen de certeza sobre la existencia del derecho pretendido solo en el grado de una aceptable verosimilitud que solo se logra al agotarse el trámite" (pp.307-308). 
En este mismo sentido, Podetti 1990 señala "el interés privado y público de asegurar la oportuna y eficaz actuación de un derecho, permite prescindir, provisionalmente de la justificación, pero no de su existencia" (p.55). Esto supone que al no existir un mecanismo de acción probatoria que se radica en la actuación del juez, da nacimiento a la verosimilitud en el derecho. En este punto el juez no puede perseguir la certeza, sino más bien una concurrencia activa de verificaciones y deducciones lógicas que comprometen el desarrollo del juicio, esto desde la ley establece las situaciones de las personas, la naturaleza de la pretensión, con el fin de esclarecer las sentencias favorables dictadas a determinada persona.

Los dos elementos señalados anteriormente el periculum in mora y la Fumus boni iuris se comprometen en la elaboración de medidas cautelares acordes, a los requerimientos de la contemporaneidad (Hernández, 2007). Por lo tanto, estas comprenden definiciones que marcan la naturaleza misma de los señalamientos que se dan en torno a las medidas cautelares, estas figuras deben ser entendidas a cabalidad y comprender los efectos negativos de no establecer un conocimiento o estructura previa para los jueces de estas aseveraciones.

\section{Reflexiones sobre la jurisprudencia constitucional a cerca de las medidas cautelares}

Las medidas cautelares tienen una importancia, la cual radica en la conformación y entendimiento de los efectos negativos que puede llegar a darse si se da una demora en el proceso judicial, a esto la medida cautelar responde como un ente garantista de derechos en el que el Estado puede resolver conflictos, esto puede llevar a la formulación de diferentes medidas cautelares, las mismas que se enfocaran en la garantía del debido proceso ante tal o cual evento.

Para esto surgen las medidas cautelares de carácter personal, que por su carácter en las garantías constitucionales no procede, sin embargo, en materia penal para que un juez dictamine medidas cautelares es fundamental la existencia del delito y la 
presunción de que una persona es responsable del delito. En materia penal las medidas cautelares se establecen en el Código Orgánico Integral Penal, y son de carácter limitativas, estas medidas consisten en: abstenerse de asistir a determinados lugares; la prohibición de ausentarse del país; ordenar la salida en los procesos de la vivienda; privar de la custodia de un menor de edad; prisión preventiva; arresto domiciliario. Entre otras medidas que se ejecutaran desde el juez quien imparta justicia (Comisión Interamericana de Derechos Humanos, 2017).

Por otro lado, están las medidas cautelares reales, las cuales basan su accionar a través de los jueces quienes por medio de su jurisdicción dictan sentencia y esta se establece en contra del patrimonio de una persona. Con esto se limita la disponibilidad de sus bienes y la disposición de un patrimonio. El fin de la misma es limitar o asegurar la responsabilidad civil de ciertos procesos, sean estos laborales, tributarios o del contencioso administrativo. Entre sus características se establece la restitución del bien (Salcedo , 2007). Como ejemplo se señala la multa que se impone al sentenciado que va dirigida a su patrimonio, por el agravio generado al Estado. Las medidas cautelares reales son: la retención, el embargo, la prohibición de enajenar bienes, el secuestro.

En el año 2008 con el establecimiento de la Constitución, se evidencia por primera vez las medidas cautelares constitucionales, las cuales se recogen en el artículo 87 de la Carta Magna que expone, que se podrán solicitar medidas cautelares y que estas servirán de protección de derechos para evitar la violación de un derecho (Asamblea Constituyente, 2008).

En tanto que, a nivel internacional la Corte Interamericana de Derechos Humanos (CIDH), establece en su artículo 27, la existencia de medidas provisionales de carácter urgente con el fin de proteger la vida de una persona, así como también precautelar la violación de derechos y garantías fundamentales (Corte Interamericana de Derechos Humanos, 2012). No obstante, es en La Ley Orgánica de Garantías Jurisdiccionales y Control Constitucional donde se reglamenta el uso de esta medida en el Ecuador (Asamblea Nacional, 2009). 
En tanto la Comisión Interamericana de Derechos Humanos establece las medidas Cautelares que manifiesta en su artículo 25 "determina que las Medidas Cautelares podrán proteger a personas o grupos de personas, siempre que el beneficiario, puedan ser situado por su ubicación geográfica o pertenencia a algún grupo, pueblo comunidad u organización". También señala la CIDH que antes de dar paso a la solicitud, la comisión requerirá al Estado involucrado, información relevante del proceso. E otorgamiento de las medidas por el Estado no constituirá prejuzgamiento por violación de los derechos protegidos por la $\mathrm{CIDH}$ (Comisión Interamericana de Derechos Humanos, 2011). Entre otros elementos que acoplan el entender las leyes desde el ámbito internacional de manejo de derechos.

Con el establecimiento de los elementos que fundamentan las medidas cautelares, entendidos desde sus características, sus variables y la conformación del periculum in mora y de la fumus boni iuris, como sustento tanto subjetivo como pragmático de las medidas cautelares es necesario establecer un entendimiento de la misma a través del orden jurídico constitucional establecido en el Ecuador, a partir de la Constitución y la Ley Orgánica de Garantías Jurisdiccionales y Control Constitucional ( LOGJCC).

Esta ley basa su fundamento en garantizar las medidas constitucionales, haciendo uso de las facultades que priman en la norma, es así que, el artículo 26 planea la finalidad de dichas medidas las cuales tendrán como objetivo, "evitar o cesar la amenaza violación de los derechos establecidos en la Constitución y en instrumentos internacionales sobre derechos humanos" (Asamblea Nacional, 2009) . Entre las características que debe tener están: prevenir, evitar o detener violaciones como la comunicación inmediata con la autoridad, deberá obtener acciones como la vigilancia policial, y sobre todo recalca que de ninguna forma podrá haber medidas privativas de libertad (Asamblea Nacional, 2009).

En el mismo sentido, se establecen los requisitos para que se den este tipo de medidas en la que se señala que la el juez, podrá decretar medidas cautelares cuando tenga conocimiento de que la persona por cualquier motivo y de forma inminente viole un 
derecho, no procederá cuando las medidas se acoplen a los parámetros de impredecibilidad judicial.

El procedimiento de las medidas cautelares es rápido y sencillo, es decir, el juez busca implementar los medios más sencillos, para proteger los derechos, cualquier persona estará en capacidad de pedir esta acción, si existe más de un juez esto se hará por sorteo, en caso de ser una petición verbal que también se puede dar, la persona tendrá que portar su documento de identificación. Esta petición se hará cuando se esté manifestando una violación de derechos constitucionales. La resolución que salga de dicho petitorio se realizará en base a los requerimientos previos, y el juez dará paso a las medidas cautelares, por otro lado, las pruebas no serán necesarias, ni la notificación normal. El juez en el caso de dar acción afirmativa al petitorio tendrá que individualizar las obligaciones positivas y negativas, para esto el juez podrá notificar mediante llamadas telefónicas, o visitas a los domicilios.

El magistrado una vez que haya promulgado este principio, podrá delegar a la Defensoría del Pueblo el buen manejo y funcionamiento de los derechos la supervisión y manejo de las medidas cautelares. La revocatoria de las medidas cautelares obedecerá cuando se cumpla los requisitos previos en la ley, o que se demuestre que no hay fundamento para que se den las medidas cautelares. En cuanto a las prohibiciones no se podrá interponer una medida cautelar contra otra medida cautelar. Y sobre la remisión de providencias el juez enviara mediante informe que sea consensuado, y estudiado bajo una doctrina jurídica que establezca las medidas cautelares adoptadas en la Corte Constitucional para su revisión y amparo en la ley (Asamblea Nacional, 2009).

\section{METODOLOGÍA}

La metodología utilizada en este artículo responde al compendio de material bibliográfico, documental y de leyes plasmadas en la Constitución, Comisión Interamericana de Derechos Humanos y La Ley Orgánica de Garantías Jurisdiccionales 
y Control Constitucional, el enfoque del mismo fue de carácter cualitativo, con énfasis en el análisis de los parámetros de aplicación práctica de las medidas cautelares. Los métodos empleados fueron el analítico - sintético e inductivo - deductivo, lo mimos que permitieron abordar el estudio desde el Derecho Constitucional, de la aplicabilidad de las medidas cautelares, haciendo referencia a sus características, su estructura y la forma que es analizada esta medida desde la Corte Constitucional, como ente regulador de la misma.

La finalidad en sí de esta investigación, es en líneas generales establecer las pautas que ayuden al entendimiento, conocimiento y comprensión de estas medidas, con el fin de aclarar preceptos constitucionales, en elementos concretos sometidos a resolución (Peñafiel, Erazo, Pozo y Narváez, 2020).

\section{APORTES GENERADOS}

Las medidas cautelares, constituyen un importante instrumento en la protección de los derechos, este principio se aplica con el fin de evitar su vulneración, además por su propia naturaleza involucra la garantía de leyes constitucionales.

Las medidas cautelares dentro del sistema de justicia del Ecuador tienen una doble dimensión, es decir, puede operar de forma individual o de manera conjunta con otra garantía constitucional. Con una excepción en la promulgación de la acción de protección.

El objetivo que persigue el establecimiento de medidas cautelares, responde a la necesidad de proteger la vulneración del derecho cuando se trata de una amenaza. Debido a varios factores las medidas cautelares deben ser aplicadas de inmediato. Esto con el fin de que los jueces sean parte activa de los procesos judiciales, los mismos involucraran una serie de parámetros de carácter legal para dictar sus sentencias.

Los presupuestos que deben cumplirse son el fumus boni iuris, la certeza del derecho y el periculum in mora, peligro en la demora (ver figura 1), es decir, se necesitará de un tiempo prudencial para establecer los lineamientos de aplicabilidad de la medida 
cautelar, esto permitirá analizar el objeto o situación pretendida desde otros lineamientos, que consentirán manejar de mejor forma las sentencias.

$\mathrm{La} \mathrm{CIDH}$ es un órgano reglamentario que establece los Derechos Humanos como norma irrestricta, en el caso que estos estuvieran siendo afectados de una manera directa. La finalidad de la CIDH es suspender su vulneración del debido proceso, y controlar al Estado su fundamentación y aplicabilidad.

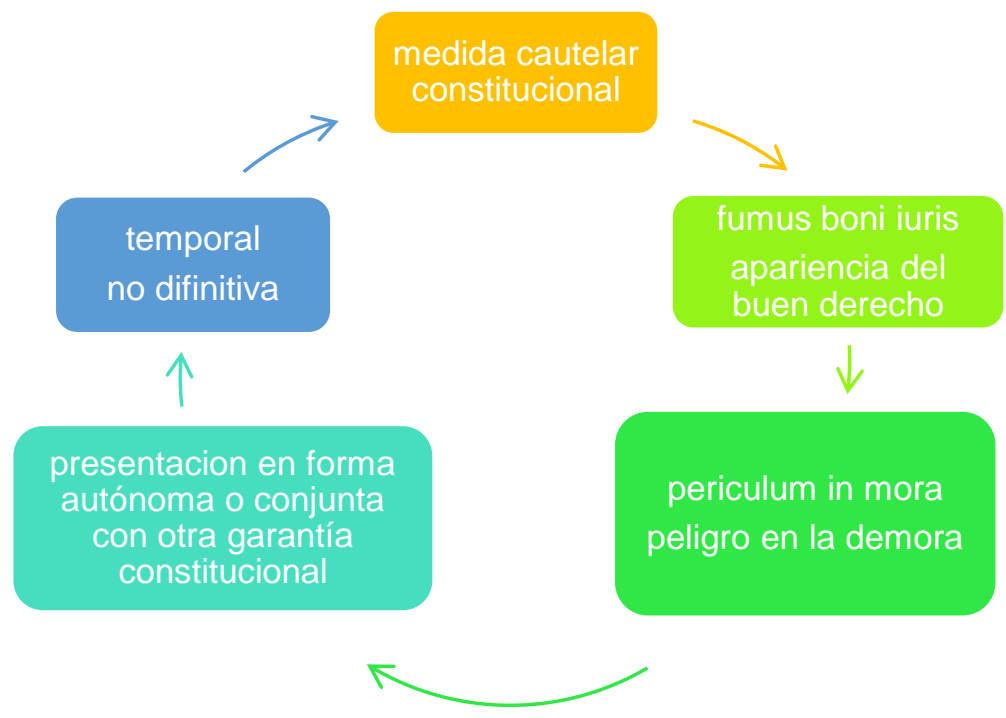

Figura 1: Las medidas cautelares constitucionales

\section{REFERENCIAS CONSULTADAS}

1. Asamblea Constituyente. (2008). Constitución de la República del Ecuador. Montecristi: Registro Oficial No. 449.

2. Asamblea Nacional. (2009). Ley Orgánica de Garantias Jurisdiccionales y Control Constitucional. Quito: Registro Oficial No 52.

3. Ávila, R. (2011). Del amparo a la acción de protección jurisdiccional. Revista IUS, 95-125. 
4. Carrera, L. (2011). La Acción de Tutela en Colombia. Revista IUS, 72-94.

5. Castilla, C. (2009). El principio pro persona en la administración de justicia . Cuestiones Constitucionales , 65-83.

6. Comisión Interamericana de Derechos Humanos. (2011). Reglamento de la Comisión de Derechos Humanos. Santiago: CIDH.

7. Comisión Interamericana de Derechos Humanos. (2017). Medidas para reducir la prision preventiva. Buenos Aires: $\mathrm{CIDH}$.

8. Corte Interamericana de Derechos Humanos. (2012). Cuadernillo de Jurisprudencia de la Corte Interamericana de Derechos Humanos. Santiago: $\mathrm{CIDH}$.

9. Corte Interamericana de Derechos Humanos. (2012). Sistema de peticion y Caos. Buenos Aires: CIDH.

10. Cueva, J. (2017). Las medidas cautelares constitucionales en el ordenamiento jurídico y sus diferencias con las cautelres ordinarias . Guayaquil: Universidad Católica Santiago de Guayaquil.

11. Due Process of Law Foundation. (2013). Independencia judicial insuficiente, prisión preventiva deformada. Masachuset: DPLF.

12. Flores, J. (2017). La potestas revocatoria de los actos administrativos. revista de Derecho Coquimbo, 191-222.

13. García, G. (2013). El Derecho a la Tutela Judicial y al debido proceso en la Jurisprudencia del Tribunal Constitucional. Estudios Constitucionales, 229-282.

14. Guzmán Chávez, M. (2019). El principio constitucional de la tutela judicial efectiva vulnerado por la acción de nulidad de sentencias. IUSTITIA SOCIALIS, 4(7), 135-145. doi:http://dx.doi.org/10.35381/racii.v4i7.366

15. Hernández, G. (2007). Medidas Cautelares en los procesos arbitrales. taxatividad o enunciación de las cautelas . Estudios Socio-Jurídicos, 183-204.

16. Kielmanovich. (2002). La oposición y levantamiento de la medida cautelar. IUS ET VERITAS, 166-181.

17. Kostenwein, E. (2017). La prisión preventiva en plural. Derecho y Praxis, $942-$ 973.

18. Marcheco, A. (2017). La Tutela Cautelar en los procesos contra la administración pública en Ecuador. Revista de derecho Valdivia, 263-285.

19. Monereo , L. (2007). La teoría del derecho en la obra de Piero Calamandrei. $\operatorname{ReDCE}, 263-298$. 
20. Peñafiel Sacoto, J. M., Erazo Álvarez, J. C., Pozo Cabrera, E. E., \& Narváez Zurita, C. I. (2020). La fundamentación y la motivación como habilitantes de la prisión preventiva. lustitia 485. doi:http://dx.doi.org/10.35381/racji.v5i8.586

21.Pérez , J., y Merino , M. (2009). Definición de Derecho Constittucional. Obtenido de Definición de Derecho Constittucional: https://definicion.de/derechoconstitucional/

22. Programa Andino de Derechos Humanos. (2010). Estado Constitucional de Derechos. Quito: Abya-Yala.

23. Salcedo , E. (2007). Las medidas Cautelares en el Arbitraje. Guayaquil: Corporación de estudios y publicaciones .

24. Steiner , C., y Uribe , P. (2012). Convención Americana sobre Derechos Humanos. Buenos Aires: Konrad Adenauer Stiftung.

25. Storini , C. (2013). La Acción de Protección en el Ecuador. Quito: Corte Constitucional del Ecuador.

26. Uribe, T. D. (2012). las medidas cautelares en la nueva constitucion del Ecuador . Quito: Juan Montaña Pinto y Angelica Porras Velasco.

27. Vaca, R. (04 de 07 de 2017). Medidas Cautelares Constitucionales . Obtenido de DerechoEcuador.com.

28. Veramendi , E. (2009). El nuevo presupuesto de la medida cautelar: La Razonabilidad. Boletin derecho, 96-110.

29.Zaidan , S. (11 de 05 de 2015). indicum. Obtenido de X. Medidas cautelares en el nuevo derecho constitucional ecuatoriano.

(C2020 por los autores. Este artículo es de acceso abierto y distribuido según los términos y condiciones de la licencia Creative Commons Atribución-NoComercial-Compartirlgual 4.0 Internacional (CC BY-NC-SA 4.0) (https://creativecommons.org/licenses/by-nc-sa/4.0/). 